\title{
ЦИФРОВАЯ ТРАНСФОРМАЦИЯ ЛОГИСТИЧЕСКИХ ЦЕНТРОВ БЕЛАРУСИ: СОСТОЯНИЕ И ПРОБЛЕМЫ
}

\author{
Л. А. Захарченко ${ }^{1}$ Г. Б. Медведева²
}

\author{
${ }^{1}$ К. э. н., доцент, доцент кафредры экономической теории и логистики учреждения образования \\ «Брестский государственный технический университет», Брест, Беларусь, e-mail: luda_az@bk.ru \\ ${ }^{2}$ К. э. н., доцент, доцент кафредры экономической теории и логистики учреждения образования \\ «Брестский государственный технический университет», Брест, Беларусь, e-mail: medgb@mail.ru
}

\section{Ресрерат}

В статье анализируется состояние, тенденции и проблемы развития логистических центров в Республике Беларусь. Основное внимание уделено возможности формирования рынка $3 \mathrm{PL}$ провайдеров. Показано, что его становление связано с необходимостью классифицировать логистические центры по международным стандартам, с перестройкой отношений всех участников цепей поставок на основе современных компетенций и с учётом цифровых технологий, таких как большие данные, облачные сервисы, блокчейн. Рассмотрено влияние применения цифровых технологий на эффективность логистических бизнес-процессов и раскрыты некоторые проблемы при практической реализации в современных условиях.

Ключевые слова: логистика, цепь поставок, логистические центры, логистические провайдеры, цифровые технологии, big date, облачные сервисы, blockchain.

\section{DIGITAL TRANSFORMATION OF LOGISTICS CENTERS IN BELARUS: STATE AND PROBLEMS}

\section{Abstract}

\section{A. Zakharchenko, G. B. Medvedeva}

The article analyzes the state, trends and problems of the development of logistics centers in the Republic of Belarus. The main attention is paid to the development opportunities of the $3 \mathrm{PL}$ provider. It is shown that the formation of the market for these providers is associated with the need to classify logistics centers according to international standards, with the restructuring of relations between all participants in the supply chains based on modern competencies and taking into account digital technologies such as big data, cloud services, blockchain. The influence of the use of digital technologies on the efficiency of logistics business processes is considered and some problems are revealed in practical implementation in modern conditions.

Keywords: logistics, supply chain, logistics centers, logistics providers, digital technologies, big date, cloud services, blockchain.

\section{Введение}

Для Беларуси формирование и развитие логистического бизнеса имеет первостепенное значение, так как позволяет ускорить интеграцию в глобальные цепочки добавленной стоимости, обеспечить устойчивое развитие экономики. В стране созданы институциональные условия для активизации роста логистики как сферы деятельности, приняты ряд стратегических документов, определяющих приоритетные направления развития логистики, в числе которых Проект программы социально-экономического развития Республики Беларусь на 2021-2025 годы [1], Республиканская программа развития логистической системы и транзитного потенциала на 2016-2020 годы [2], Концепция Государственной программы «Цифровое развитие Беларуси на 2021-2025 годы» [3] и другие.

Согласно Концепции развития логистической системы Республики Беларусь на период до 2030 года целевыми ориентирами логистической системы Республики Беларусь следует считать: а) рост позиции Республики Беларусь в мировом рейтинге по индексу эффективности логистики LPI до уровня не ниже 50; б) рост по отношению к 2016 г. объема логистических и транспортно-экспедиционных услуг в 2 раза; в) увеличение доходов от транзита по отношению к 2016 г. в 2 раза [4].

Во всех этих документах также рассматриваются вопросы развития и повышения эффективности логистической инфраструктуры, качества оказываемых логистических услуг (включая повышение эффективности функционирования уже созданных логистических центров и формирование пула мультимодальных логистических центров, провайдеров 3PL и 4PL уровня), повышение роли логистических центров как структур по индустриализации бизнеса, перехода к индустрии 4.0 .

В проекте дорожной карты по развитию логистической системы Республики Беларусь на период до 2030 года, который предполагает пошаговый сценарий достижения стратегических целей государства в сфере логистики, среди семи предлагаемых к реализации блоков развития логистики выделено повышение эффективности функционирования логистических центров и проведение

сертификации субъектов логистической деятельности (логистических центров, логистических операторов) на соответствие требованиям СТБ 2306-2013 и СТБ 2345-2013 [5].

Состояние и проблемы развития логистических центров в Республике

О степени развития логистики в Республики Беларусь можно судить по результатам опубликованного очередного исследования эффективности развития логистики (Logistics Performance Index, LPI). B нынешнем рейтинге Беларусь занимает 103-е место - это на 17 строчек выше, чем в предыдущей версии 2016 г., когда мы были 120-ми, в 2012 г. занимала 91-е место, в 2014 г. - 99-е. Общая сумма баллов по LPI - 2,57 против 2,40 в 2016 г. самый высокий был в 2012 году - 2,61. Таким образом, значительного улучшения позиции Республики Беларусь по данному показателю не произошло.

В европейских странах, которые граничат с Беларусью, наивысшую строчку в рейтинге LPI занимает Польша (28-е место в списке), дальше располагаются Литва (№ 54), Украина (№ 65), Латвия (№ 70). Если сравнивать со странами Евразийского экономического союза (ЕАЭС), то Казахстан улучшил свою позицию в рейтинге, переместившись с 77-го места (2016 г.) на 71-е (2018 г.), Россия «перепрыгнула» с 99-го сразу на 75-е место, Армения также показала значительный рост, переместившись со 141-го места (2016 г.) на 92-е (2018 г.), Кыргызстан расположился ниже Беларуси и занял 108-е место (в 2016 г. - 146-е). Высший балл в Logistics Performance Index - 5 у Германии, которая в нынешнем, как и в предыдущем рейтинге, занимает первое место. Таким образом, у Беларуси есть ориентир, к которому необходимо стремиться [6].

Степень развития логистики и ее эфффективность во многом определяется эффективностью функционирования логистической инфраструктуры, под которой следует понимать материальнотехническую систему, предназначенную для удовлетворения потребностей организаций различных форм собственности, производства и населения и в продукции, работах и услугах. Одним из объектов логистической инфраструктуры являются логистические центры, 
Вестник Брестского государственного технического университета. 2021

обладающие всеми необходимыми средствами для оказания логистических услуг сторонним организациям на коммерческой основе различными операторами.

В современных условиях вопросы развития логистической инфраструктуры, ее основных объектов, в том числе логистических центров привлекают внимание многих ученых, поскольку в теоретических исследованиях и в практической деятельности нет единой точки зрения на многие вопросы, связанные с содержанием, структурой, тенденциях развития категорий и процессов. С этих позиций определенный интерес вызывают работы Ф. Д. Венде, О. Рыкалиной, В. Степанова, А. Л. Носова, В. И. Черенкова, О.В. Климовеца, А. В. Таничева, Т. Г. Зориной, С.М. Горячевой, О. М. Овечкиной, Д. В. Курочкина и других.

Целью создания логистических центров является доставка грузов от поставщика к потребителю в кратчайшие сроки и с наименьшими финансовыми затратами. Логистические центры способствуют повышению эффективности и результативности логистических процессов и удовлетворенности клиентов, т. е. стремятся к комплексному обслуживанию. Развитая система логистических центров позволяет сокращать цепи поставок, оптимизировать товарные потоки, повышать маневренность поставок.

Логистические центры имеют материально-вещественную форму (транспортную сеть, транспортный парк, терминалы, склады, объекты водо- и энергоснабжения и другое), что составляет их логический потенциал, а использование данного потенциала или (экономическое содержание логистических центров) происходит через реализацию определенных функций, которые весьма разнообразнь и находятся в постоянном развитии. Можно выделить три вида функций: основные логистические (транспортировка, складирование хранение, упаковка, комплектация, управление запасами и заказами информационные услуги, продвижение и маркетинг); вспомогательные функции (экспедирование грузов, оформление перевозочных и таможенных документов, декларирование, предварительное уведомление таможенных органов, страхование, аренда контейнеров, поддонов и другой тары); дополнительные функции (финансовые услуги, бухгалтерские услуги, телекоммуникационные услуги, консалтинговые услуги, услуги парковки и коммерческо-делового обслуживания). Таким образом, здесь обеспечивается управление сквозными товароматериальными потоками. Основной задачей данного логистического центра является эффективная интеграция деятельности всех внутренних его участников, а также внешних производителей и потребителей, при условии обеспечения высокого качества транспортно-логистического сервиса. Содержания логистических услуг и связанных с ними компетенций в настоящий момент определяется государственными стандартами СТБ 2046-2010 «Транспортнологистический центр. Требования к техническому оснащению и транспортно-экспедиционному обслуживанию», СТБ 2047-2010 «Логистическая деятельность. Термины и определения», СТБ 2133-2010 «Классификация складской инфраструктуры», СТБ 2306-2013 «Услуги логистические. Общие требования и процедура сертификации», СТБ 2345-2013 «Логистическая деятельность».

В Республике Беларусь логистические центры развиваются ускоренными темпами. Так, относительно 2015 года количество логистических центров в Беларуси выросло в 3,8 раза и в 2019 году, по данным БелНИИТ «Транстехника», зарегистрировано 60 логистических центров, из них 16 были введены в эксплуатацию в 2019 году. В этих центрах действуют: 67 складов временного хранения и таможенных складов; 19 пунктов таможенного оформления; около 400 складов общего пользования; контейнерных терминалов, включая 145 площадок для обработки контейнеров различных видов и вместимости; 56 автостоянок. Объем услуг, оказанных логистическими центрами, составил в 2019 году 223,6 млн рублей, показав спад в 0,9\% относительно прошлогоднего показателя [7].

В Беларуси действуют логистические центры различной направленности: таможенные, складские, транспортные, распределительные. В структуре оказанных логистических услуг транспортно-логистические центры занимают $56,3 \%$, оптово-логистические - 5,2 \%, все остальные логистические услуги оказывают прочие объекты складской инфраструктуры, включая арендованные. С этих позиций возникает необходимость оценки разноплановых логистических операторов и центров по уровню международных стандартов, исключить несоответствие тех или иных объектов национальным стандартам. Только в этом случаи мы сможем построить адекватную и конкурентоспособную систему логистических операторов Беларуси и сможем использовать мощный технический потенциал страны, ее географическое положение.

Еще одной из проблем развития логистических центров является нерациональное размещение уже созданных логистических центров, так $75 \%$ расположены в Минской области и 12,5 \% - в Брестской, в остальных регионах Беларуси их крайне мало. Те, что функционируют, находятся в основном в управлении госоператора - компании «Белтаможсервис». Некоторые частные объекты, как например: комплекс «Белагротерминал» в Сморгони или торговологистический центр «Марко» в Витебске - имеют свою специфику и обслуживают внутренние грузопотоки. Правда, в последнее время «Белагротерминал» начал оказывать услуги и сторонним компаниям, в т. ч. и специфические: в логистическим центре имеются маслобаковые танки для хранения растительных масел емкостью практически 2,4 тыс. куб. м. Это, наверное, единственный подобного рода объект в Беларуси, способный обслуживать грузопотоки с такой наливной продукцией. Из частных компаний в регионах в сфере развития складской логистики активно работает «Бремино Групп». Компания еще два года назад ввела в эксплуатацию современный ТЛЦ в районе ППК «Брузги», идет подготовка к реализации аналогичного проекта в ППК «Берестовица». Сейчас компания реализует крупный мультимодальный промышленно-логистический комплекс в поселке Болбасово, что рядом с Оршей.

В современных условиях существенно меняются требования клиентов к услугам. Клиенты ориентируются на индивидуальный подход к ним, уже на «входе» задается множество условий и критериев, и они ожидают выгодного решения, причем иногда просят дать несколько вариантов логистических схем с целью оптимизации своих логистических бюджетов. Таким образом, комплексность услуг становится одним из определяющих факторов выбора логистического оператора. По данным Европейской логистической ассоциации, комплексность услуг логистических компаний в странах Евросоюза составляет около 73 \%, в то время как в Беларуси этот показатель по различным источникам составляет от $17 \%$ до 23 \% [7]. Логистическими центрами Беларуси предоставляется не более 20 видов услуг из 88, регламентированных СТБ 2306-2013. Для сравнения: в Германии логистические центры оказывают в среднем 70, а в Японии - 110 услуг. Таким образом, логистические центры оказывают отдельные виды логистических услуг, причем их стоимость условно небольшая, но не конкурентная. Такое положение подтверждают основные составляющие логистического индекса - «пользовательские» оценки работы таможни, состояния инфраструктуры, международных перевозок, качества логистики и логистических компетенций, возможностей отслеживания движения грузов и своевременности доставки. И если рассмотреть этот показатель детально, то по таможенным услугам наша страна занимает 112-е место, по качеству логистических услуг - 85 место, для сравнения, Россия 71 место.

Среди логистических центров, оказывающих наибольшее количество услуг, можно назвать РУП «Белтаможсервис», СООО «Брествнештранс», ОАО «Торгово-логистический центр «Озерцо-Логистик», ОАО «Белмагистральавтотранс», СП «Транзит» ООО. Комплексное обслуживание транзитных грузов обеспечивает запущенный в эксплуатацию новый транспортно-логистический центр «Каменный Лог Белтаможсервис», который находится на 147-м км автомобильной дороги (имеющей международное значение - М7 Минск - граница Литвы - Вильнюс и входящей в 9-й трансъевропейский транспортный коридор, рядом с пунктом пропуска «Каменный Лог»). Надо отметить, что данный центр соответствует европейскому уровню.

На сегодняшний день логистические центры имеют право самостоятельно определять свою классность. Так, с 1 ноября 2013 года в соответствии с СТБ 2306-2013 «Услуги логистические. Общие требования и процедура сертификации» введена добровольная сертификация логистических услуг с целью гарантии их качества, объемов оказываемых услуг и определения работы операторов логистических услуг на арендуемых площадях. Однако по данным статистики только 4 центра прошли сертификацию логистических услуг на соответствие требованиям государственного стандарта.

Причиной такого положения дел является тот факт, что нет единых критериев отнесения объектов инфраструктуры к тому или иному виду логистических центров, а главное, нет сопряженности 
в методиках оценки логистических центров в Беларуси с международной методикой. Безусловно, невозможно, чтобы все операторы придерживались одних требований или отвечали им, но сегодня достаточно остро стоит вопрос о необходимости разработки документа, согласно которому можно было бы оценить разноплановых логистических операторов на уровень 3PL. Этого требует международное сотрудничество, но необходимо сразу учитывать особенности логистики в Беларуси. Нам не только нужно грамотно проанализировать эволюцию развития логистики в развитых государствах, но и использовать мощный технический потенциал своей страны, ее географическое положение.

Отсутствие такого документа привело к тому, что сегодня у нас на рынке наблюдается тенденция, когда массово появляются компании, называющие себя 3PL-оператором. Хотя, по сути, они не понимают, каким показателям им нужно соответствовать. Исходя из этого, спорным остается вопрос о развитии рынка $3 \mathrm{PL}$-провайдеров в Беларуси. Если, по мнению одних авторов, он слабо развит, то, по мнению других, он уже сформировался. По мнению третьих к логистическим центрам, предоставляющим услуги на уровне $3 \mathrm{PL}$ можно отнести «AsstrA», «Балтспед логистик», «БелРусИнвест», «СЛЦ Двадцать четыре», «Доминик», «Белсотра».

\section{Необходимость и возможность развития 3PL-операторов} в Республике Беларусь.

В международной статистике различают пять видов логистических операторов: 1PL, 2PL, 3PL, 4PL и 5PL. Возникает вопрос: как оценить или сертифицировать имеющихся в стране операторов? Первые два вида являются традиционными, набор услуг и уровень сервиса достаточно известны, а главное, эти виды себя изжили и уходят с рынка, поскольку 2PL - это простая транспортировка грузов по контракту между подрядчиками и заказчиками железнодорожным, автомобильным и авиационным транспортом.

Сегодня речь идет о развитии рынка логистических услуг, с присутствием на нем $3 \mathrm{PL}$ провайдеров. Не вызывает сомнения, что рынок таких провайдеров широко востребован в настоящее время, поскольку их функции значительно расширены, они могут, помимо перевозки, обеспечить складское хранение и переработку груза; также они ведут учет и управление запасами, могут подготовить экспортно-импортную документацию, т. е. оказать дополнительные услуги со значительной добавленной стоимостью.

Переход к деятельности 3PL-провайдеров весьма сложен, и не-

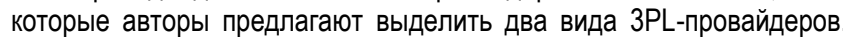
Первый $3 \mathrm{PL}$ - простой, осуществляющий экспедирование грузов (мультимодальные перевозки, оптимизация маршрута), и $3 \mathrm{PL}$ - комплексный или контрактная логистика (управление поставками и заказами). В целом же фоормат 3PL-операторов (Third Party Logistics Provider) является наиболее продвинутой формой логистического аутсорсинга. На аутсорсинг полностью передается комплекс логистики [8].

C этих позиций для развития 3PL-провайдеров большое значение имеют сложившиеся отношения между логистами и их заказчиками, правильно ли они понимают интересы каждого, совпадают ли их интересы, доверяют ли они друг другу. Для заказчиков основным драйвером развития аутсорсинга является возможность сосредоточиться на конкурентных преимуществах своей компании, сокращение издержек, надежность партнера. Заказчики должны четко осознавать положительный эффект от передачи логистики на аутсорсинг, быть уверены в компетенции логистических компаний. Логистические компании выступают за развитие долгосрочных партнерских отношений. В то же время эти отношения не являются застывшими. Ввиду изменяющихся внешних условий, рыночной конъюнктуры, развития новых технологий и т. д. компания может принимать решение о передачи деятельности на аутсорсинг, затем она может быть возвращена внутрь компании как функция.

Что касается рынка $3 \mathrm{PL}$-провайдеров в Республике Беларусь, то здесь существует множество ограничений, которые затрудняют его полноценное развитие. Прежде всего, как показал мировой опыт, логистические операторы 3PL-появились вслед за крупными производителями FMCG либо крупными торговыми сетям. У нас же 3PL провайдеры создавались в основном на базе транспортно-логистических центров, что в некоторой степени препятствует их полноценному развитию.
Затем сдерживающим фактором эффективного роста логистических центров является и слабый внутренний спрос на такие услуги со стороны ключевых предприятий реального сектора экономики, поскольку основная часть услуг по перевозкам и хранению грузов, управлению логистикой осуществляется собственными службами предприятий (более 70 \% логистических операций). При том, что только 3-4 \% государственных предприятий эффективно построили логистику, среди частных компаний 18-20 \% имеют качественно выстроенные логистические цепочки. Этим можно объяснить и достаточно большие затраты на логистические операции, так уровень логистических издержек в два раза превышает мировой показатель и находится в пределах 20-25 \% объема ВВП республики. Оптимизировать все эти затраты может логистический оператор за счет грамотного управления потоками, автоматизации складских и логистических процессов. К тому же такая тенденция идет вразрез со сложившейся общемировой практикой, так как одним из определяющих показателей развития рынка логистических услуг является уровень логистического аутсорсинга. Наилучшие показатели в этой области показывают США - 81,3\% [9].

Можно перечислить еще ряд сдерживающих факторов развития 3PL провайдеров в Республике Беларусь. Это - недостаток инвестиций, приводящий к замедленному развитию всей логистической инфраструктуры, в том числе и логистических центров; недостаточное использование информационных технологий, облегчающих взаимодействие с клиентами и осуществление различных процедур; нехватка высококвалифицированных кадров, способных заниматься логистическим управлением на всех уровнях и другие. Тем не менее, развитие сегмента 3PL-логистики в современных условиях поддерживается за счет:

а) усложнения процесса импорта товаров (обязательная маркировка по стандартам ЕАЭС). Эту задачу может решить логистический провайдер в процессе доставки, что подразумевает целый комплекс услуг: транспортировку, складские услуги, организацию работ с грузом и прочее;

б) изменения географической структуры грузопотоков в пользу стран «третьего мира», прежде всего, стран Юго-Восточной Азии и Африки, с которыми ожидается дальнейший рост торговли. Для белорусского рынка 3PL очень важно и перспективно дальнейшее развитие импорта с Китаем. Для этого на территории китайско-белорусского индустриального парка «Великий камень» создается «сухой порт» и комплексный логистический центр, с целью максимально задействовать складские площади и возможности белорусских центров для терминальной обработки грузов ЕАЭС и Китая, включая формирование коммерческих партий для дальнейшей отправки получателю за пределами нашей страны;

в) серьезные планы стран Евросоюза по снижению выбросов СО2 диктуют соответствующие решения для логистических провайдеров. В частности, в Австрии уже с 1 января 2021 года въезд на территорию страны с использованием многосторонних разрешений ЕКМТ разрешен только грузовым автомобилям класса "Евро-6". Наверняка подобные требования будут быстро распространяться и на другие страны Евросоюза;

г) у $3 \mathrm{PL}$-провайдера больше вариантов решения проблем, связанных с сезонным дефицитом провозных возможностей из-за ежегодного сокращения квот разрешений на международные автомобильные перевозки в/из стран ЕС;

д) импортно-экспортные грузопотоки все больше концентрируются в руках крупных игроков рынка, которые проводят комплексные закупки логистических услуг. Для логистических операторов в условиях усиливающейся конкуренции на первый план выходят такие факторы, как возможность экономии на масштабе и получение синергетического эффректа. Поэтому на рынке укрепляют свои позиции и увеличивают рыночную долю наиболее крупные и сильные игроки, как за счёт органического роста, так и за счёт поглощения менее успешных конкурентов.

Развитию рынка 3PL-провайдеров способствует и Программа FIATA «Управление цепями поставок», реализуемая в Республике Беларусь Центром «БАМЭ-Экспедитор», которая призвана повысить компетентность руководителей, высших топ-менеджеров национальных транспортно-логистических компаний и дать теоретические и практические знания для последующего перехода от 3PL 
к 4PL-провайдерам. При этом не надо забывать, уровень специализации белорусского рынка логистических услуг значительно ниже, чем на Западе, следовательно, часть известных бизнес-моделей к белорусскому рынку просто пока не применимы.

Дальнейшее развитие логистических центров связано с необходимостью перехода к статусу 4PL. B этом случае 3PL-оператор должен быть готов к внедрению новых технологий, задуматься о консалтинге как продаваемой услуге и об инновационном подходе как практике, но инициаторами подобных процессов на этом уровне в подавляющем большинстве случаев служат клиенты.

Появление 4PL-провайдеров связано с интеграционными процессами в мировой экономике, с необходимостью глобального управления цепями поставок и логистическими системами. Его деятельность основана на концепции SCM (Управление цепями поставок) и использовании современных цифровых технологий.

4PL-провайдер - это логистический интегратор, то есть единый поставщик логистических услуг, которому заказчик передает управления собственными цепями поставок "от начала до конца», т. е. одному аутсорсеру. Таких компаний в мире насчитывается около десятка. Это крупные логистические операторы, которые обслуживают мировые компании, такие как Sony, Toshiba и другие. Поэтому говорить о развитии логистики такого уровня в Беларуси преждевременно. Оператор данного уровня не имеет никаких своих активов, он организует работу логистической цепи, является интегратором, поэтому может работать только тогда, когда на рынке уже имеется большое количество 3PL-операторов. 4PL-провайдер значительно глубже взаимодействует со всеми компаниями-участниками поставки продукции и сам планирует всю логистическую цепь, а также управляет логистическими бизнес-процессами в компании-заказчика. Большое значение в 4PL-логистике принадлежит управлению информационными (а не товароматериальными) потоками и оперативному принятию решения на основе использования информационно-компьютерных технологий. Таким образом, заказчик передает провайдеру всю информацию о бизнесе фирмы, о закупках и поставках, о клиентах, объемах продаж, финансовых показателях, а также о ключевых конкурентных преимуществах. А логистический провайдер, обрабатывая данную информацию в собственной информационной системе, обеспечивает движение материальных потоков заказчика оптимальным образом с точки зрения снижения затрат и удовлетворения потребителей. Преимуществом 4PL-провайдеров является логистическое обслуживание с высокой добавленной стоимостью, т. е. подбор услуг под каждый конкретный заказ, под отдельного клиента. Для их создания необходимо изменить само понимание логистики, перейти от контроля за работой транспорта, склада и процессов закупки к передаче логистическому оператору на аутсорсинг управление всей цепочкой поставок. Для многих руководителей в современных условиях это весьма затруднительно.

Не так давно в логистике появился новый вид провайдеров - 5PL (Fifth Party Logistics) - это интернет-логистика на основе использования IT-технологий. У специалистов отсутствует мнение по данному вопросу, многие эксперты считают, что 5PL-провайдеры сейчас не существуют и это лишь теория, что на самом деле это совершенствование 4PL-системы: автоматизация и оптимизация работы по поиску логистических решений. Однако в странах ЕС активно выделяют денежные средства на развитие 5PL. Так, в течение 20-30 лет на территории Евросоюза может быть разработана единая логистическая информационная сеть, а она, в свою очередь, даст толчок

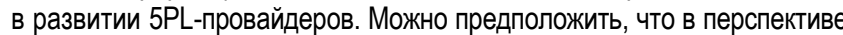
5PL-провайдеры будут вытеснять провайдеров более низкого уровня, включая в свой набор оказываемых услуг дополнительно услуги сетевого сервиса. Выбор же того или иного вида логистического провайдера основан на степени готовности любого предприятия передать на аутсорсинг только какую-то часть функций или всех их в полном объеме.

\section{Роль цифровизации в развитии рынка $3 \mathrm{PL}$ провайдеров}

На ведение логистического бизнеса в ближайшие годы, в том числе на развитие более совершенных форм провайдеров, по прогнозам экспертов, наибольшее влияние окажет цифровизация. Это объективный процесс, который создаёт условия для увеличения выручки за счет расширенного взаимодействия с клиентами по цифровым каналам и снижения затрат по их обслуживанию, снижая бизнес- риски за счет онлайн-платежей и уменьшая негативные эфффекты от нехватки квалифицированных специалистов.

Цифровизация в логистики проходит по пяти основным направлениям: инфраструктура, технологии, коммуникации, информация и компетенции участников логистической системы. Тем самым она изменяет все функции, которые выполняют логистические центры, и способствует развитию более совершенных форм этих центров, в первую очередь становлению 3PL-провайдеров. Главные технологии цифровой экономики, которые сегодня активно внедряются в бизнес, могут быть применены в деятельности логистических центров: анализ больших данных (Big Data) и интернет-вещей, облачные сервисы и решения, блокчейн, 3D-печать, робототехника и автоматизация, использование дронов и другие.

Поскольку будущие виды провайдеров, как сказано выше, имеют дело в большей степени с информационными потоками, что вызывает рост трудозатрат на информационный обмен с другими участниками цепей поставок, эти затраты уже сейчас неоправданно высоки и продолжают расти. К тому же имеющиеся стандартные инструменты обмена потоками данных требуют от участников рынка компетенций, которые на сегодняшний день достигает сравнительно небольшое число компаний, при этом отсутствует единая логистическая информационная система в компаниях. Все это замедляет принятие управленческих решений и обслуживание клиентов, не позволяет в реальном времени отслеживать ситуации на рынке логистических услуг. Отсюда особую актуальность вызывает внедрение цифровых технологий, связанных с информационным обслуживанием логистической деятельности, в частности внедрение технологии анализа больших данных.

Управляя логистическими процессами, возникает необходимость накапливать, анализировать и управлять огромным количеством данных. Однако объем данных, который генерируется в мире, растет в геометрической прогрессии, и текущих ИТ-инструментов становится недостаточно. Для решения потенциальных проблем была создана концепция «Больших данных», которая позволяет получить более точную и прозрачную оперативную информацию, улучшить качество предоставляемых услуг, ускорить принятие решений, повысить уровень сервиса обслуживания клиентов, улучшить процесс доставки товаров за счет анализа дорожного состояния, погодных условий и т. д. Системы сбора, хранения, обработки и интерпретации данных при правильном управлении будут служить «хабами» для обмена данными между поставщиками, каналами сбыта и 3PL-провайдерами.

Наибольшей популярностью с точки зрения приложения технологий обработки больших данных пользуется оптимизация и совершенствование процессов доставки: маршрутизация доставки и оперативное управление доставкой с позиций расширения периметра контроля за доставкой и снижения логистических рисков. Управления рисками позволяют своевременно идентифицировать, оценить и среагировать на рисковые события, использовать данные из внутренних и внешних источников (данные из мобильных датчиков и RFID-меток, записи видео и разговоров по мобильному телефону и другие). При этом сокращается роль человеческого фактора, а следовательно, снижается количество возможных ошибок. Эффрективное управление такими системами позволит обеспечить многостороннюю миграцию данных между WMS, FMS, EMS, SLM (система «закрытой петли» для управления торговыми представителями) [10].

Концепция больших данных тесно связана с облачными технологиями. В общем смысле под облачными сервисами (технологиями) можно понимать модель предоставления сетевого доступа к общему пулу конфигурируемых вычислительных ресурсов (серверов, приложений, систем хранения и т. д.), которые могут быть быстро предоставлены и освобождены с минимальными усилиями по управлению и необходимости взаимодействия с провайдером.

Основные преимущества использования облачных технологий в логистике связаны с возможностью обеспечения взаимодействия всех участников логистической цепи (поставщик, перевозчик, потребитель) между собой и доступа к единой базе данных в режиме реального времени. Хранение данных на виртуальных серверах - это безопасно, надёжно и экономически выгодно. Последнее связано с экономией вложений в ИТ-оборудование: здесь нет необходимости со временем менять и обновлять техническое оснащение по мере роста бизнеса, когда появится спрос на дополнительные мощности, которые можно получить из облака. Вместо приобретения и установки 
собственных серверов предприятие арендует их у провайдера и управляет ими через интернет, оплачивая только фактическое использование оборудования для обработки и хранения данных. Экономия средств на техобслуживании «железа» (содержании сервера, штата администраторов и покупке программного обеспечения). В среднем облачные решения позволяют сократить ИТ-расходы на $20 \%$. Самое главное в облачных технологиях - это их доступность. Уже сейчас значительная часть компаний в США и Евросоюзе «сидят в облаках». А по прогнозам до 2030 года их будут использовать примерно 45 \% предприятий по всему миру [11].

В Республике Беларусь с 2012 года действует СООО «Белорусские облачные технологии» - первый структурный оператор, платформы которого размещены и функционируют на базе собственного дата-центра в Республиканском центре обработки данных (РЦОД) и в Единой республиканской сети передачи данных (ЕРСПД). Услуга Colocation (размещение оборудования) - это услуга по физическому размещению серверного и телекоммуникационного оборудования Клиента в стандартных стойках Республиканского центра обработки данных beCloud.

В Беларуси действует ряд программ, связанных с облачными решениями. Программа 4logist специально разработана для автоматизации и упрощения бизнес-процессов экспедиционных и транспортных компаний. Решение работает по принципу SaaS (сервис как услуга), доступна в любом месте и в любое время посредством интернета.

Transinfo.by - первый белорусский портал грузоперевозок, действующий с 2007 года, оказывает помощь транспортным и торговым предприятиям, экспедиторам в поиске свободного транспорта и грузов. Transavto.by - белорусская транспортно-информационная система, которая содержит базу грузов и машин, информацию о наличии очередей на границах и другую информацию. Можно назвать и ряд других программ. Использование cloud-решений позволяет предприятиям транспортно-логистической отрасли значительно сократить не только финансовые, но и временные затраты. Провайдеры предоставляют сервис в течение часа с момента поступления запроса. Заказчику не нужно ждать доставку оборудования, расходовать время на сборку, установку и тестирование. Все работы проводятся удаленно, быстро и с соблюдением самых высоких требований безопасности.

Но существуют факторы, препятствующие распространению облачных технологий в логистике. Во-первых, это опасение за сохранность конфиденциальной информации, утрата которой неминуемо приведет к банкротству бизнеса. Специалисты же считают, что размещение бизнес-данных в облаке - способ куда более надёжный, чем хранение информации на серверах непосредственно в офисе, поскольку потерять данные из облака достаточно сложно. За сохранность данных на серверах отвечают бекапы (резервное копирование данных) и снимки системы (снапшоты). Это позволяет восстановить данные в случае критических ситуаций (например, сбоя операционной системы внутри виртуального сервера).

Во-вторых, IT-системы, которые устарели, сложно перенести в облако, так как они построены на уникальных архитектурах, не подразумевающих возможность миграции. В итоге переход в облако требует переработки многих приложений, специфической экспертизы, большого количества ресурсов. Однако вложенные в облака ресурсы многократно отбиваются в будущем. Можно предположить, что очень многие логистические компании уже в ближайшие годы хотели бы получить от разработчиков готовые аналитические сервисы, способные предсказать потребность в тех или иных товарах и услугах в различных регионах. Имея на руках точные аналитические выкладки, предприятия смогут более эффективно развивать самые разные виды грузовых перевозок, определять логистические потоки.

Следующей цифрровой технологией, на которой следует остановиться с позиций взаимоотношений всех участников цепи поставок, и в том числе с провайдерами, является блокчейн-технология. Данная технология является инструментом распределения базы данных позволяющей хранить информацию о всех транзакциях и изменениях. Она появилась в 2008 году, а в 2015 г. была создана платформа etherium blockchain, где впервые была применена технология смарт- контрактов. Это новый способ управления данными, исключающий неидентифицируемые изменения и позволяющий автоматизировать процесс проведения транзакций с использованием смарт-контрактов. При такой технологии обеспечивается полная прозрачность, которая делает невозможным взлом системы пользователями и таким образом устраняет необходимость участия третьих лиц.

В логистике блокчейн может создать быструю и надежную систему заключения контрактов между продавцом и покупателем, надежную систему взаимодействия поставщика и покупателя, упростить обмен конфиденциальными данными для различных перевозчиков и грузоотправителей, проводить мониторинг экономических потоков (перемещение товаров, сумма сделок, условия хранения и другая информация). В условиях реального времени компании могли бы создавать решения для финансирования всей цепочки поставок. Концепция блокчейна трудна для понимания многими логистами, и, несмотря на ее большой потенциал, практически не развивалась, хотя ряд компаний запустили пилотные проекты с целью тестирования данной технологии. Согласно прогнозу IDC (International Data Corporation), опубликованному в июле 2018 года, ежегодные мировые расходы на blockchain вплоть до 2022 года будут расти темпами, близкими к $100 \%$, и возрастут с 1,5 миллиардов 2018 год до 11,7 миллиардов долларов в 2022 году. Но полноценное использование данной технологии будет возможно только после 2030 года [12]. В мировой практике нет однозначного понимания будущего развития данной технологии. Уже существуют экспериментальные проекты, успешно применяющие блокчейн в логистике. К примеру, CargoX - один из стартапов, который полностью посвятил себя внедрению блокчейна в логистическую отрасль с помощью общедоступной сети Ethereum для безопасной проверки транзакций документов. Также UPS и BNSF Railway Уоррена Баффета присоединились к блокчейну в транспортном альянсе. Но для того, чтобы эффективно принять блокчейн, логистические компании должны оцифровывать, стандартизировать и очистить свои данные. Это позволит внедрить общеотраслевой стандарт и сформировать экосистему партнеров по цепочке поставок, чтобы использовать стандарт в общей неразрешенной среде блокчейна.

Сдерживает развития данной технологии и отсутствие законодательной базы, регламентирующей ее применение, разрешения спорных вопросов и защиты участников и их цифровых активов в цепочке. Сама концепция основана на доверии среди участников, поскольку отсутствуют формальные регулятивные нормы.

\section{Заключение}

Общий тренд, который наблюдается сегодня на рынке логистических услуг - оптимизация затрат на логистику. Один из верных способов добиться этого - передать логистические функции на аутсорсинг 3PL-провайдерам; для развития рынка таких провайдеров в Республике Беларусь есть определенные проблемы, но и определенные предпосылки. Основным драйвером в развитии логистики и провайдеров на сегодняшний день является внедрение цифровых технологий. Именно они предоставляют широкие возможности компаниям для сокращения затрат, улучшения качества сервиса, повышения удовлетворенности клиентов, снижения логистических рисков и другие конкурентные преимущества. За этими технологиями будущее, пока компании не способны извлекать дополнительные ценности из них. Это связано с рядом причин: нет четкого понимания сущности данных технологий, не хватает соответствующей компетенции для их внедрения и не хватает финансовых ресурсов, но цифровые технологии являются в современных условиях фундаментом конкурентоспособности.

\section{Список цитированных источников}

1. Основные положения проекта программы социально-экономического развития Республики Беларусь на 2021-2025 годы [Электронный ресурс]. - Режим доступа: http://brest-region.gov.by. Дата доступа: 10.03.2021.

2. Об утверждении Республиканской программы развития логистической системы и транзитного потенциала на 2016-2020 годы [Электронный ресурс] / Национальный правовой Интернетпортал Республики Беларусь. - Режим доступа: https://pravo.by/. Дата доступа: 12.02.2021. 
3. Цифровое развитие Беларуси на 2021-2025 годы ГЭлектронный ресурс] / Национальный правовой Интернет-портал Республики Беларусь. - Режим доступа: https://pravo.by/. - Дата доступа: 12.02.2021.

4. Об утверждении Концепции развития логистической системы Республики Беларусь на период до 2030 года [Электронный ресурс] / Национальный правовой Интернет-портал Республики Беларусь. - Режим доступа: https://pravo.by/. - Дата доступа: 12.02.2021.

5. Проект Дорожной карты по развитию логистической системы Республики Беларусь на период до 2030 года. Юлектронный ресурс]. - Режим доступа: https://infotrans.by/2020/05/06/ - Дата доступа: 14.02 .2021$.

6. Глобальный рейтинг LPI [Электронный ресурс]. - Режим доступа: https://lpi.worldbank.org/ international/global - Дата доступа: 14.022021.

7. Обзор рынка транспортно-логистических услуг Беларуси [Электронный ресурс]. - Режим доступа: https://aser.by/wp-content/uploads/2020/12/Rynok... - Дата доступа : 18.02.2021.

8. Стапран, Д. А. Логистический аутсорсинг: Что о нем думают логисты и заказчики / Д. А. Стапран, И. О. Проценко // Логистика и управление цепями поставок. - 2017. - № 2. - С. 38-48.

9. Захарченко, Л. А. Развитие логистики в Республике Беларусь: проблемы и перспективы / Л. А. Захарченко, Г. Б. Медведева // Логистика - Евразийский мост: материалы 12-ой Межд. научн.-практ. конф., Красноярск: 18-20 мая 2017 г. / Красноярс. гос. аграр. ун-т. Ч. 1. - Красноярск, 2017. - С. 72-77.

10. Ивенин, Р. Е. Технологии обработки Больших данных в логистике и УЦП / Р. Е. Ивенин // Логистика и управление цепями поставок. - 2018. - № 03 (86). - С. 40-46.

11. Григорьев, А. Облачные решения в управлении цепями поставок [Электронный ресурс] - Режим доступа: https://logist.fm/publications/. - Дата доступа: 22.02.2021.

12. Колосов, А. М. Перспективы технологии blockchain применительно к автоматизации процессов закупочной деятельности / А. М. Колосов // Логистика и управление цепями поставок - 2018. - № 06 (89). C. 31-38.

\section{References}

1. Osnovnye polozheniya proekta programmy social'no-ekonomicheskogo razvitiya Respubliki Belarus' na 2021-2025 gody [Elektronnyj resurs]. - Rezhim dostupa: http://brest-region.gov.by. Data dostupa: 10.03.2021.
2. Ob utverzhdenii Respublikanskoj programmy razvitiya logisticheskoj sistemy i tranzitnogo potenciala na 2016-2020 gody [Elektronnyj resurs] / Nacional'nyj pravovoj Internet-portal Respubliki Belarus'. Rezhim dostupa: https://pravo.by/. - Data dostupa: 12.02.2021.

3. Cifrovoe razvitie Belarusi na 2021-2025 gody [Elektronnyj resurs] / Nacional'nyj pravovoj Internet-portal Respubliki Belarus'. - Rezhim dostupa: https://pravo.by/. - Data dostupa: 12.02.2021.

4. Ob utverzhdenii Koncepcii razvitiya logisticheskoj sistemy Respubliki Belarus' na period do 2030 goda [Elektronnyj resurs] / Nacional'nyj pravovoj Internet-portal Respubliki Belarus'. - Rezhim dostupa: https://pravo.by/. - Data dostupa: 12.02.2021.

5. Proekt Dorozhnoj karty po razvitiyu logisticheskoj sistemy Respubliki Belarus' na period do 2030 goda. [Elektronnyj resurs]. - Rezhim dostupa: https://infotrans.by/2020/05/06/ - Data dostupa: 14.02.2021.

6. Global'nyj rejting LPI [Elektronnyj resurs]. - Rezhim dostupa: https://lpi.worldbank.org/ international/global - Data dostupa: 14.022021.

7. Obzor rynka transportno-logisticheskih uslug Belarusi [Elektronnyj resurs]. - Rezhim dostupa: https://aser.by/wp-content/uploads/2020/12/Rynok... - Data dostupa : 18.02.2021.

8. Stapran, D. A. Logisticheskij autsorsing: $\mathrm{CH}$ to o nem dumayut logisty i zakazchiki / D. A. Stapran, I. O. Procenko // Logistika i upravlenie cepyami postavok. - 2017. - № 2. - S. 38-48.

9. Zaharchenko, L. A. Razvitie logistiki v Respublike Belarus': problemy i perspektivy / L. A. Zaharchenko, G. B. Medvedeva // Logistika - Evrazijskij most: materialy 12-oj Mezhd. nauchn.-prakt. konf., Krasnoyarsk: 18-20 maya 2017 g. / Krasnoyars. gos. agrar. un-t. - CH. 1. Krasnoyarsk, 2017. - S. 72-77.

10. Ivenin, R. E. Tekhnologii obrabotki Bol'shih dannyh v logistike i UCP / R. E. Ivenin // Logistika i upravlenie cepyami postavok. - 2018. № 03 (86). - S. 40-46.

11. Grigor'ev, A. Oblachnye resheniya v upravlenii cepyami postavok [Elektronnyj resurs] - Rezhim dostupa: https://logist.fm/publications/. Data dostupa: 22.02.2021.

12. Kolosov, A. M. Perspektivy tekhnologii blockchain primenitel'no k avtomatizacii processov zakupochnoj deyatel'nosti / A. M. Kolosov // Logistika i upravlenie cepyami postavok - 2018. - № 06 (89). - S. 31-38.

Материал поступил в редакцию 05.05.2021 